\title{
Effect of Current Density on Crystallographic Orientation, and Oxidation Behavior of Copper Plated on Aluminum Substrate
}

\author{
Bambang Soegijono $^{1 *}$, Ferry Budhi Susetyo ${ }^{1,2}$, Evi U.M. Situmorang ${ }^{1,3}$ and Yusmaniar $^{4}$ \\ ${ }^{1}$ Department of Physics, Universitas Indonesia \\ Depok 16424, Indonesia \\ Email: naufal [AT] ui.ac.id \\ ${ }^{2}$ Department of Mechanical Engineering, Universitas Negeri Jakarta \\ Jakarta 13220, Indonesia \\ Email: fbudhi [AT] unj.ac.id \\ ${ }^{3}$ School of Medicine and Health Sciences, Universitas Khatolik Atmajaya \\ Jakarta 12930, Indonesia \\ Email: evisitmg [AT] yahoo.com \\ ${ }^{4}$ Department of Chemistry, Universitas Negeri Jakarta \\ Jakarta 13220, Indonesia \\ Email: yusmaniar [AT] unj.ac.id \\ ${ }^{*}$ Corresponding author's email: naufal [AT] ui.ac.id
}

\begin{abstract}
In this work, the electroplating of copper on an aluminum substrate without electrochemical surface treatment was investigated. Electroplating of copper on aluminum substrate was prepared from copper sulfate electrolyte bath with various current densities $1 \mathrm{~mA} / \mathrm{cm}^{2}, 3 \mathrm{~mA} / \mathrm{cm}^{2}, 10 \mathrm{~mA} / \mathrm{cm}^{2}$, and $40 \mathrm{~mA} / \mathrm{cm}^{2}$. The effects of current density on the samples properties were characterized using a different technique. The surface morphology, crystallographic orientation, and corrosion resistance of the Copper film were analyzed using a scanning electron microscope, energy dispersive spectroscopy (SEM-EDS), X-ray diffractometer (XRD), and potentiostat. The samples' surface morphology is changed with different current densities because nucleation is driven by transferring the copper ion rate onto the aluminum substrate. The Cu-10 sample exhibits (111) peak higher and the best corrosion resistance than other samples. Moreover, $\mathrm{Cu}-1$ samples have shifted to positive corrosion voltage $\left(\boldsymbol{E}_{\text {corr }}\right)$ than the other samples.
\end{abstract}

Keywords- Electroplating, Copper, Aluminum, Copper sulfate bath

\section{INTRODUCTION}

The copper layer, prepared by copper deposition on an aluminum substrate, offers many benefits over bulk copper, namely cost advantage[1], [2]. Copper deposition can be achieved by many techniques, such as physical vapor deposition (PVD) [3], chemical vapor deposition (CVD) [4], electroplating [5] and electro less plating [6]. Electroplating one of the easiest to control and cheapest for deposition methods [7]. Electroplating of copper has been used widely in many industrial fields to improve decorative, antifouling, antibacterial, and corrosion properties [8]. The electroplating of copper often used sulphate [9], chloride [10], sulphate-chloride [11] gluconate [12], and acetate [13] solution. In the electroplating process, the microstructure of deposited depends on the electroplating parameters, among which is current density [1]. Moreover, as the current density of electrodeposition of copper change, varies surface morphology, crystallographic orientation and crystallite size are formed [13]

Electroplating copper directly onto an aluminum substrate is difficult to practice. Copper is an active metal with low ionization energy. Hence it does not easy to deposit copper ions onto a passivized surface such as aluminum[14]. Kanungo et al. reported electroplating copper onto aluminum by immersing aluminum substrate from an electrolyte containing perchloric acid as a complexing agent prior plating [15]. Jiahe et al. was reported copper layers deposited on aluminum by galvanic displacement [16]. The other research used double zincate pretreatment before deposited copper onto aluminum substrate [1], [17]. Genna et al. optimized the sandblasting process before the electrodeposition of copper on the aluminum substrate by a feed-forward neural network [14]. This method will achieve the best adhesion of the 
coating without complex equipment or solution which is harmful to the environment. But the process of the sandblasting is used special protective equipment because the dust of the sand is harm full for the healthy. Moreover, waste of the sand after sandblasting processing is need for treatment before release on nature. For that reason, in this paper it used abrasive sandpaper for surface treatment of the substrate before the electroplating process. Moreover, this paper is also study and observes the surface morphology, crystallographic orientation, and corrosion behavior of copper film plated on aluminum substrates in sulfate solutions with various current densities.

\section{EXPERIMENTAL METHODS}

The copper layer has been electroplated using DC Power Supply with various current densities. The various current densities used were $1 \mathrm{~mA} / \mathrm{cm}^{2}, 3 \mathrm{~mA} / \mathrm{cm}^{2}, 10 \mathrm{~mA} / \mathrm{cm}^{2}$, and $40 \mathrm{~mA} / \mathrm{cm}^{2}$, and it was designated as $\mathrm{Cu}-1, \mathrm{Cu}-3, \mathrm{Cu}-10$, and $\mathrm{Cu}-40$, respectively. The copper electroplating was carried out for 120 minutes in the electrolyte at temperature $30{ }^{\circ} \mathrm{C}$. The electrolyte was $300 \mathrm{ml}$ solution containing $\mathrm{CuSO}_{4} \cdot 5 \mathrm{H}_{2} \mathrm{O}(220 \mathrm{~g} / \mathrm{L})$, and sulfuric acid (10 mL/L). Before electroplating, the electrolyte solution was stirring for 1 hour to make homogeneous. Copper plate (99.99\%) was used as an anode, and an aluminum alloy plate (see Table 1) was used as a cathode. The distance between the copper plate and aluminum plate was maintained for $50 \mathrm{~mm}$ to achieve better copper layers. Before the electroplating process, the samples were polished with SiC grit 220, 500, and 2000 then ultrasonic cleaning with acetone. The electroplating processes of copper layers were performed without stirring the solution.

Table 1: Composition of Al alloy substrate (wt.\%) for the electroplated copper layer

\begin{tabular}{c|c|c|c}
\hline Element & $\mathbf{M g}$ & $\mathbf{F e}$ & $\mathbf{A l}$ \\
\hline Concentration & 1.49 & 1.63 & balance \\
\hline
\end{tabular}

The surface morphology and oxygen content were capture and observe using SEM-EDS (FE-SEMFEI INSPECT F50 EDAX EDS Analyzer). The crystallographic orientation has been analyzed using XRD (Malvern Panalytical Ltd., UK). The XRD observations were performed with scans resolution $0.01^{\circ}$ of $2 \theta$ from $40^{\circ}$ until $80^{\circ}$. The corrosion behaviors of the copper layer were used potentiodynamic polarization observation (Digi-Ivy DY2311). The $\mathrm{Ag} / \mathrm{AgCl}$ as a reference electrode (RE), platinum wire as a counter electrode (CE), and the aluminum as the working electrode (WE) with exposing area of $1 \mathrm{~cm}^{2}$. The potentiodynamic polarizations were perform in $3.5 \%$ sodium chloride $(100 \mathrm{~mL})$ with scan rate $50 \mathrm{mV} / \mathrm{s}$ from $-1.5 \mathrm{~V}$ to $0.5 \mathrm{~V}$.

\section{RESULTS AND DISCUSSION}

\subsection{SEM-EDS}

Figure 1 shows SEM images detail electroplated samples of $\mathrm{Cu}-1, \mathrm{Cu}-3, \mathrm{Cu}-10$, and $\mathrm{Cu}-40$. The surface of the electroplated samples is seen uniform. At lower current density $(\mathrm{Cu}-1)$, grain form sharper than at higher current density $(\mathrm{Cu}-40)$. Moreover, a more compact surface is seen on $\mathrm{Cu}-1$ than $\mathrm{Cu}-40$, based on Figure 1.

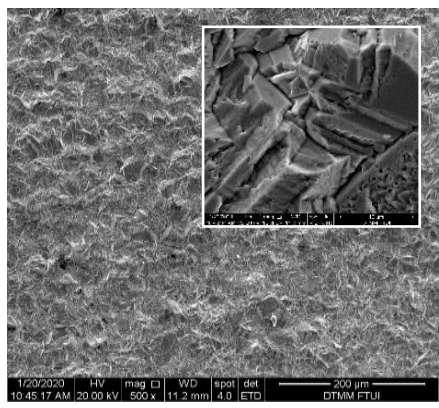

(a)

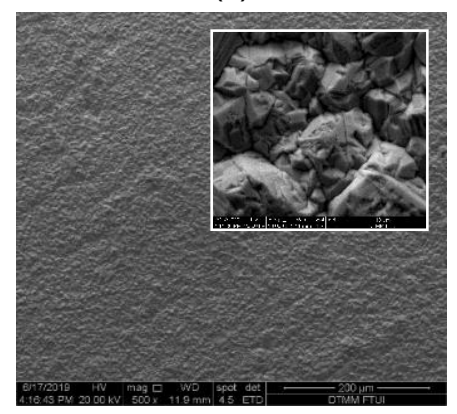

(c)

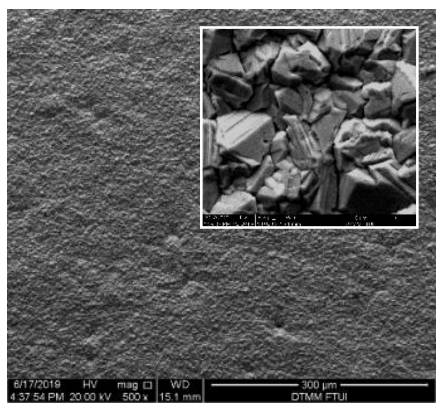

(b)

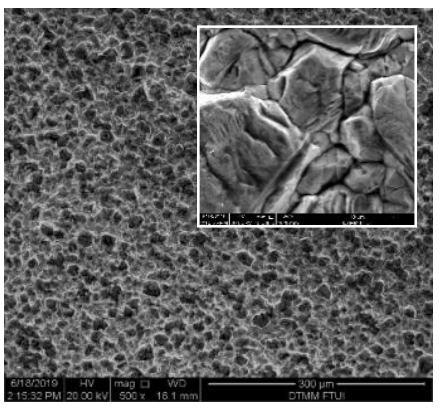

(d)

Figure 1: SEM Images of copper film at different current density (a) $\mathrm{Cu}-1$, (b) $\mathrm{Cu}-3$, (c) $\mathrm{Cu}-10$, and (d) $\mathrm{Cu}-40$ 
The increased supply of copper ions at higher current density $(\mathrm{Cu}-40)$ facilitates the decrease in sharp edges and more smaller of copper grains, as shown in Figure 1 (c) compare to Figure 1 (a). The surface morphology of the samples is change with different current densities because nucleation is driven by the rate transferring of copper ions onto the aluminum substrate. The increase of the current density is influenced by the increase of the throwing power copper ions into aluminum surfaces [13]. It seems that the $\mathrm{Cu}-10$ sample has smooth and compact morphology surfaces than the other samples - the higher current density resulting in a high crystal nucleation rate that leads to a fine-grain structure. The fine-grained structure leads to a tremendous large amount of grain boundary, resulting in higher resistivity and rigidity [18]. A similar morphology is found in the other's research and it has been plated copper onto aluminum with current density1 A/dm². [19]. Other parameter such as temperature of the solution would significantly affect the surface morphology of the copper layer [20].

Knowing the chemical composition of the copper film is important. Other element incorporate in copper film may affect the properties of the film such as wetting property. The surface of the copper layer was characterized using the EDS apparatus to examine the elemental composition. The FE-SEMFEI INSPECT F50 EDAX EDS Analyzer is used for surface observation. Figure 2 shows the EDS spectra electroplated samples of $\mathrm{Cu}-1, \mathrm{Cu}-3, \mathrm{Cu}-10$, and $\mathrm{Cu}-40$ onto aluminum substrate. The copper layer's EDS analysis usually shows a significant peak of copper and a small peak of oxygen [21]. The other research only found copper and oxygen before treatment, and after treatment, the sulfur atom on the copper surfaces are found, this is caused by inhibitor adsorption on the copper surfaces [22]

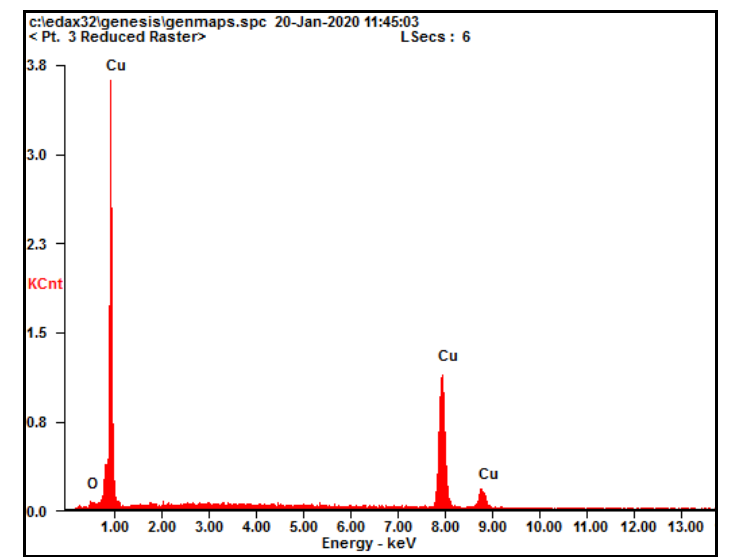

(a)

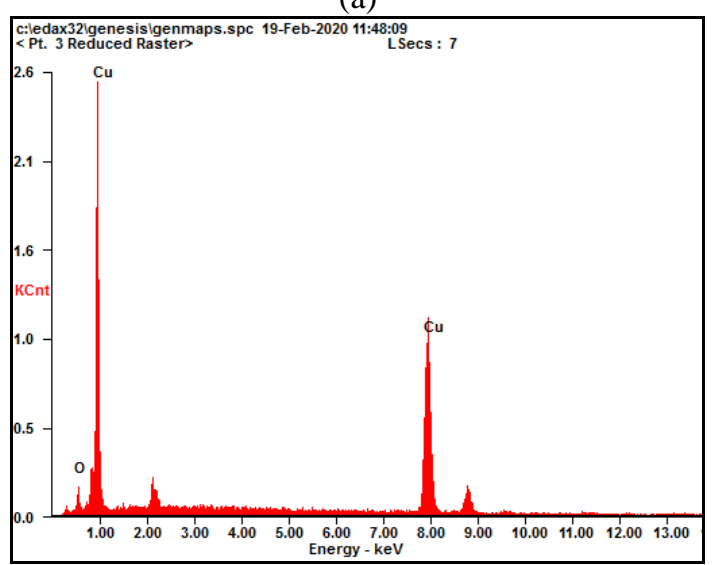

(c)

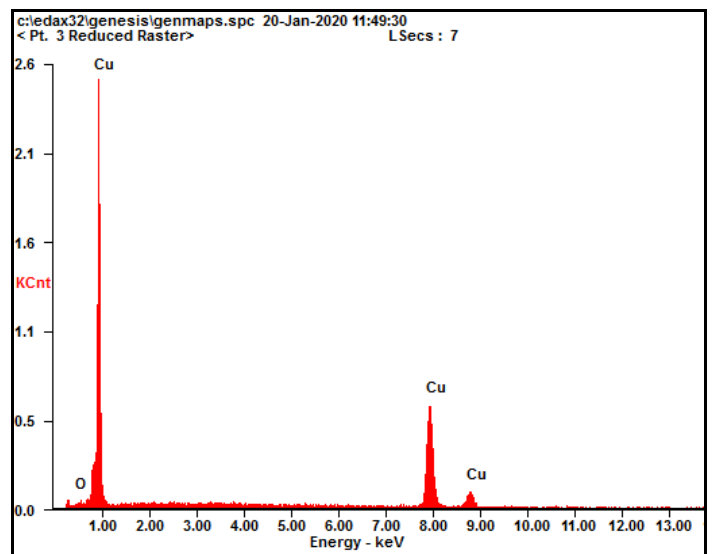

(b)

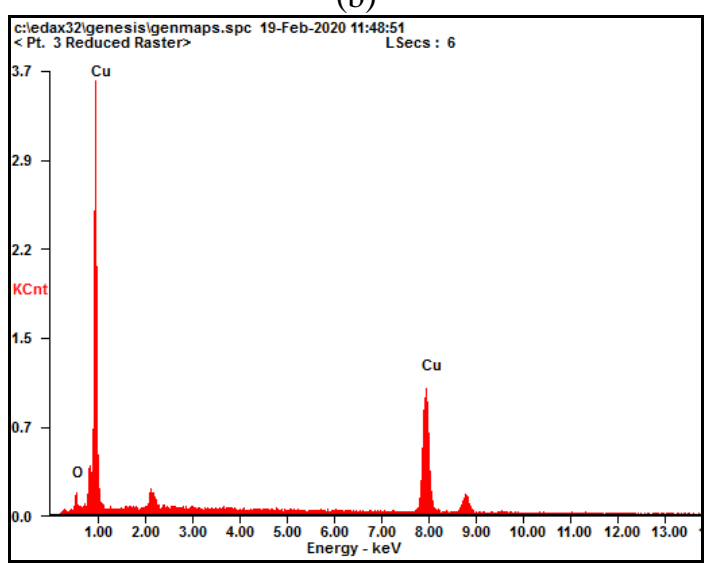

(d)

Figure 2: EDS Spectra at Different Copper Electroplated Samples (a) $\mathrm{Cu}-1$, (b) $\mathrm{Cu}-3$, (c) $\mathrm{Cu}-10$, and (d) $\mathrm{Cu}-40$

Base on the EDS spectra in Figure 2, the percentage of phase or element is resumed in Table 2. Table 2 shows the resulting of EDS analysis electroplated samples of $\mathrm{Cu}-1, \mathrm{Cu}-3, \mathrm{Cu}-10$, and $\mathrm{Cu}-40$ onto aluminum substrates. 
Table 2: EDS analyze at different electroplated copper samples onto an aluminum substrate

\begin{tabular}{l|c|c}
\hline \multicolumn{1}{c|}{ Sample } & O (Wt \%) & Cu (Wt \%) \\
\hline $\mathrm{Cu}-1$ & 00.93 & 99.07 \\
$\mathrm{Cu}-3$ & 01.30 & 98.70 \\
$\mathrm{Cu}-10$ & 02.97 & 97.03 \\
$\mathrm{Cu}-40$ & 03.44 & 95.56 \\
\hline
\end{tabular}

Based on Table 2, only the copper and oxygen element are shown. There is no iron, or other elements are shown base on EDS analysis. The rise in current density leads to an increase in oxygen content on the surface of the copper layer by increase. This is indicated the copper layer was fabricated with $40 \mathrm{~mA} / \mathrm{cm}^{2}$ is easy to form $\mathrm{CuO}$ than $1 \mathrm{~mA} / \mathrm{cm}^{2}$. The solution contain also $\mathrm{OH}^{-1}$ ion resulting from dissociation of water. The current can generate oxygen gas at anode. But the sample was placed at cathode where the Hydrogen gas may be generated. The oxygen can also exit due to Oxygen dissolved which reach $8 \mathrm{mg} / \mathrm{L}$. Oxygen incorporate at copper film may come from oxygen dissolved which is dissociate more at higher current density and lead to form copper oxide or form as oxygen adsorption at the surface of the film.

\subsection{XRD}

The X-ray diffraction (XRD) usually used to determine the phase of the materials. It has the detection limit. If the phase contain in the material is less than the limit detection of the XRD equipment, the phase will not appear at the diffraction pattern. The XRD patterns of electrodeposited copper with various current densities are shown in Figure 3. The phase observed is only copper. The copper oxide is not detected. It may be due to the small amount which is less than the detection limit. Three diffraction peaks are displayed at 43.97 $\pm 0.1,51.08 \pm 0.1$, and 74.68 (022) for (111), (002), and (022) plane, respectively. Comparison with copper standard (JCPDS 04-0836), copper is FCC structure system, and three characteristic diffraction peaks of copper are located at $43.7^{\circ}, 50.7^{\circ}$, and $74.3^{\circ}$ with (111), (200) and (220) planes respectively [23].

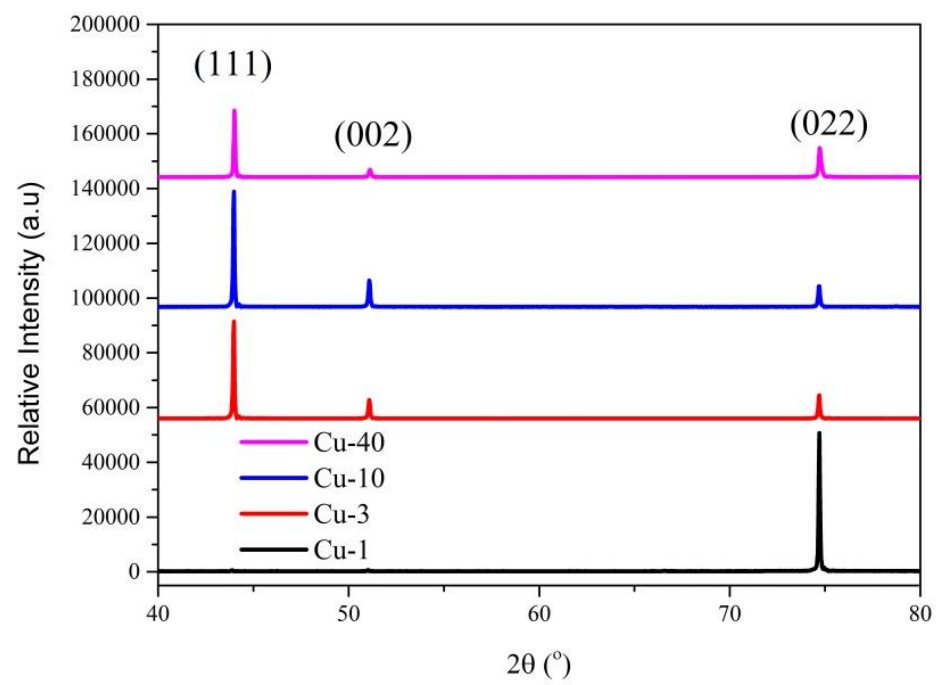

Figure 3: XRD Pattern of Electroplated Copper Samples

The crystal system of various samples is Cubic FCC with Space Group Fm-3m base on refinement with highscore plus software (Table 3). Moreover, the samples show different intensities of (111), (002), and (022) crystal plane; this is similar to the salee et al. report [19]. Jianhong et al. investigate $\mathrm{K}_{3} \mathrm{Fe}(\mathrm{CN})_{6}$ addition on electro less copper plating. Without $\mathrm{K}_{3} \mathrm{Fe}(\mathrm{CN})_{6}$ addition, preferred orientation is seen on (111) plane, and more addition of $\mathrm{K}_{3} \mathrm{Fe}(\mathrm{CN})_{6}$ will increase the $(022)$ plane resulting in the preferred orientation of (002) plane [6]. These phenomena are contradictive with our result, the preferred orientation of (111) plane is seen on $\mathrm{Cu}-3, \mathrm{Cu} 10$, and $\mathrm{Cu}-40$. Moreover, decrease the current density to $1 \mathrm{~mA} / \mathrm{cm}^{2}(\mathrm{Cu}-1)$ was resulting preferred orientation on $(022)$ plane. The $\mathrm{Cu}-10$ sample has the highest intensity of (111) plane than the other samples, and the highest intensity of (022) plane is seen on the $\mathrm{Cu}-1$ sample (about 5000 a.u).

Figure 4 shows the difference phenomena of Full Width at Half Maximum (FWHM) at different the current densities. Based on Figure 4 (a), FWHM for the peak (111) has continuously decreased with the rise of the current density. This result has contradictive with the previous study where increasing current densities gave effect to increase the FWHM [17]. This might cause by of zincate pretreatment effect that was used before electroplating of copper. Figure 4 (b) shows that FWHM for the peak (002) has continuously decreased when the current density increases. But the peak (111) increase as the current density increase. 
Table 3: Crystal parameter of the various samples

\begin{tabular}{l|c|c|c|c}
\hline \multicolumn{1}{c}{ Parameter } & \multicolumn{4}{c}{ Samples } \\
\cline { 2 - 5 } \multicolumn{1}{c}{ Cu-1 } & Cu-3 & Cu-10 & Cu-40 \\
\hline Crystal System & Cubic FCC & Cubic FCC & Cubic FCC & Cubic FCC \\
Space Group & Fm-3m & Fm-3m & Fm-3m & Fm-3m \\
Rwp (\%) & 8.99 & 6.730 & 6.926 & 5.984 \\
GOF & 2.7 & 1.20 & 1.38 & 0.96 \\
\hline
\end{tabular}

Figure 4 (c) also show similar phenomena, FWHM for the peak (022) has continuously increased when the current density is increase.

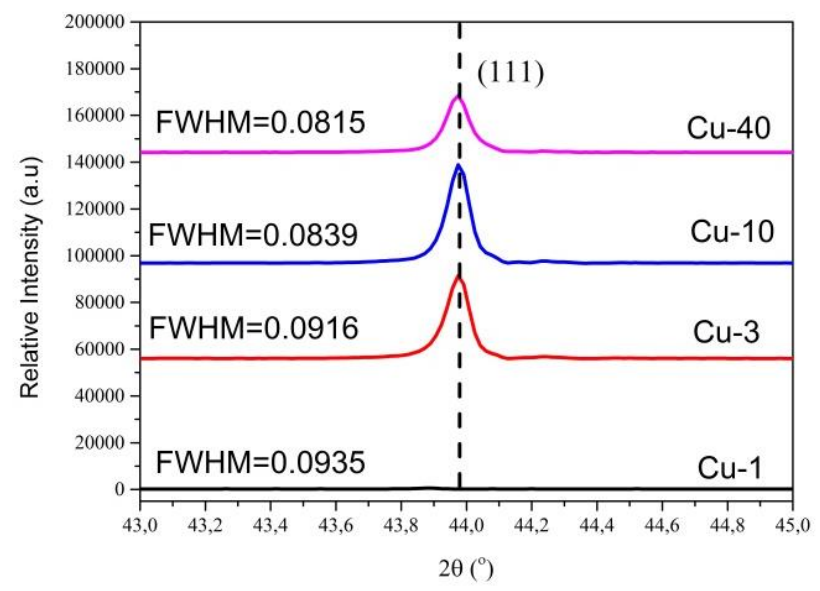

(a)

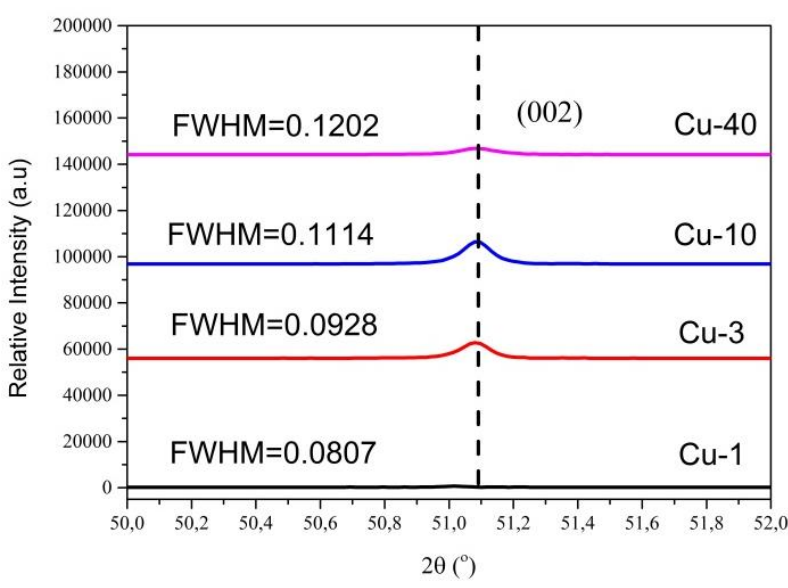

(b)

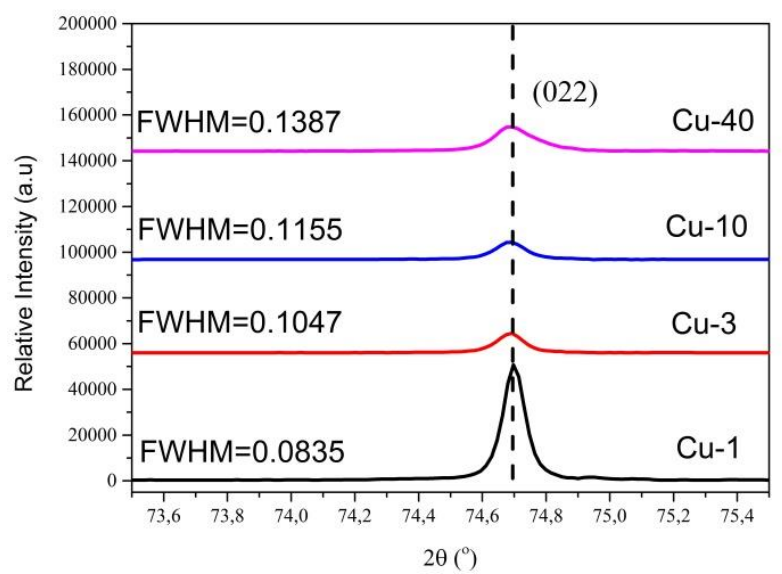

(c)

Figure 4: The FWHM Various Electroplating Samples (a) (111), (b) (002), and (c) (022)

The FWHM of the various sample used to determine the crystallite size of the copper film. Crystallite size can be calculated using the following Debye-Sherrer equation [6], [23].

$$
D=k \lambda / \beta \cos \theta
$$

Where $\mathrm{D}$ is crystallite size, $\mathrm{k}$ is constant $(1), \lambda$ is the wavelength $\left(1.54056 \mathrm{~A}^{\circ}\right.$ for $\left.\mathrm{Cu}-\mathrm{K}\right), \beta$ is $\mathrm{FWHM}$ in radian, and $\theta$ is Bragg angle in radian. Crystallite sizes of the various sample copper plating onto an aluminum substrate are presented in Table 4.

Based on Table 4, crystallite sizes of the sample are reduced with the decrease of current density from $40 \mathrm{~mA} / \mathrm{cm}^{2}$ until $3 \mathrm{~mA} / \mathrm{cm}^{2}$. But on the one $\mathrm{mA} / \mathrm{cm}^{2}$ of current density, crystallite size becomes higher than other samples. This phenomenon is caused by shifting the preferred orientation from (111) plane to (022) and the value of the FWHM copper layer sample. 
Table 4: Crystallite size of the various samples

\begin{tabular}{l|l|l|l|l}
\hline \multicolumn{1}{c}{ Parameter } & \multicolumn{4}{c}{ Samples } \\
\cline { 2 - 5 } \multicolumn{1}{c}{ Cu-1 } & \multicolumn{1}{c}{ Cu-3 } & Cu-10 & Cu-40 \\
\hline The crystallite size $(\mathrm{nm})$ & 125 & 97.74 & 106.71 & 109.86 \\
hkl & $(022)$ & $(111)$ & $(111)$ & $(111)$ \\
FWHM & 0.0835 & 0.0916 & 0.0839 & 0.0815 \\
$2 \theta$ & 74.7 & 43.98 & 43.98 & 43.98 \\
\hline
\end{tabular}

It is clear that the preferred orientation depend on many factors such as current density and the solution

\subsection{Potentiodynamic Polarization}

To explore corrosion resistance, potentiodynamic polarization was performed [24], [25]. Figure 5 shows the potentiodynamic polarization curve of various samples in $3.5 \%$ sodium chloride. Anodic dissolution of various sample copper layer in $3.5 \%$ sodium chloride is described as the following equation[26]:

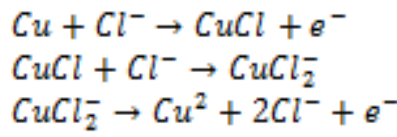

Based on equation 2, $\mathrm{CuCl}$ can be readily adsorbed and insoluble. However, the adhesion of $\mathrm{CuCl}$ on the surface of copper is not enough to protect the copper from corrosion. In equation 3, the $\mathrm{CuCl}$ is transformed into a soluble copper (I) chloride complex, which can quickly diffuse into the bulk of the solution[26].

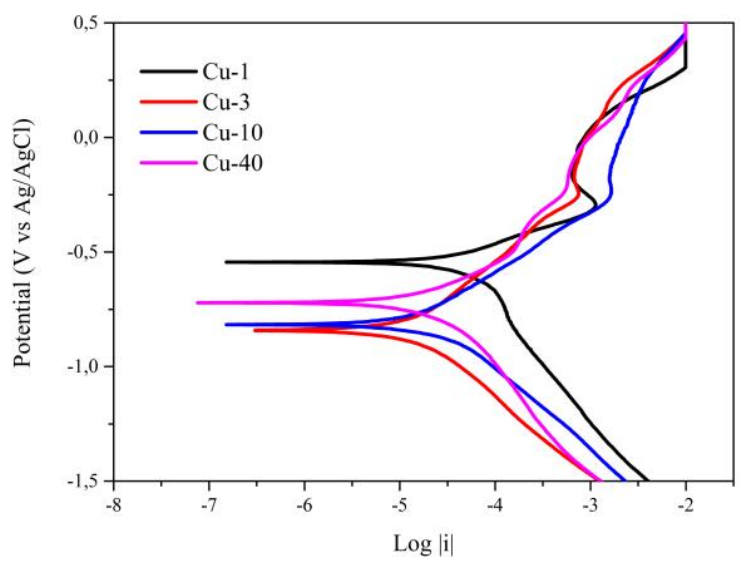

Figure 5: Variation Potentiodynamic Polarization Samples in $3.5 \mathrm{wt} \%$ Sodium Chloride

As shown in Table 5, the entire sample shows different corrosion current density, corrosion potential, and corrosion rate phenomena. Sample $\mathrm{Cu}-1$ has more positive corrosion potential ( $\mathrm{E}_{\text {corr }}$ ) and also has the highest corrosion rate than the other sample. The $\mathrm{Cu}-10$ sample exhibits the best corrosion resistance than other samples because it has a peak intensity of (111) plane higher than the other sample. For the copper layer, (111) peak is a densely packed one; hence preferred growth along [111] direction offers additional benefits like better corrosion resistance[17]. Moreover corrosion current density (Icorr) for entire electroplated copper sample are less than previous research $\left(\mathrm{I}_{\text {corr }}=6.06 \times 10^{-5} \mathrm{~A} / \mathrm{cm}^{2}\right)[27]$. This indicated the entire sample has better corrosion resistance than bulk copper.

Table 5: Potentiodynamic polarization measurement of the samples at various current densities

\begin{tabular}{l|c|c|c}
\hline \multicolumn{1}{c|}{ Sample } & Icorr $\mathbf{( A / c ^ { 2 } )}$ & Ecorr(V vs Ag/AgCl) & Cor Rate (mmpy) \\
\hline $\mathrm{Cu}-1$ & $2.98 \mathrm{E}-05$ & -0.544 & 0.325 \\
$\mathrm{Cu}-3$ & $9.36 \mathrm{E}-06$ & -0.842 & 0.102 \\
$\mathrm{Cu}-10$ & $6.22 \mathrm{E}-06$ & -0.817 & 0.067 \\
$\mathrm{Cu}-40$ & $9.70 \mathrm{E}-06$ & -0.722 & 0.106 \\
\hline
\end{tabular}

\section{CONCLUSIONS}

Copper electroplating onto aluminum substrates with various current densities has been successfully fabricated. The surface morphology of the samples is change with different current densities because nucleation 
is driven by the rate transferring of copper ions onto the aluminum substrate. There are three significant peaks of (111), (002), and (022) based on XRD investigation at various samples of the copper layer. The Cu-10 sample exhibits (111) peak higher and the best corrosion resistance than other's samples. The $\mathrm{Cu}-1$ samples have the highest positive voltage $\left(\mathrm{E}_{\mathrm{Corr}}\right)$ than the other samples.

\section{ACKNOWLEDGEMENT}

The authors gratefully acknowledge financial support from Ministry of Research, Technology and Higher Education of the Republic of Indonesia Kementrian Riset, Teknologi dan Pendidikan Tinggi under grant Hibah Penelitian Disertasi Doktor No: NKB-1827/UN2.R3.1/HKP.05.00/2019

\section{REFERENCES}

[1] A. Augustin, K. Udaya Bhat, K. R. Udupa, and A. C. Hegde, "Electron Microscopic Study of Nodules formed during Electrodeposition of Copper on Aluminium," vol. 2, pp. 371-374, 2015.

[2] F. Budhi Susetyo, E. M. H. Situmorang, S. Luthfiya, and B. Soegijono, "Copper Electrodeposition onto Aluminum from a Copper Acid Baths in the Presence of Poly Ethylene Glycol (PEG)," MATEC Web Conf., vol. 218, pp. 0-4, 2018.

[3] M. Proust, F. Judong, J. M. Gilet, L. Liauzu, and R. Madar, "CVD and PVD copper integration for dual damascene metallization in a $0.18 \mu$ m process," Microelectron. Eng., vol. 55, no. 1-4, pp. 269-275, 2001.

[4] H. Matsushima, A. Bund, W. Plieth, S. Kikuchi, and Y. Fukunaka, "Copper electrodeposition in a magnetic field," Electrochim. Acta, vol. 53, pp. 161-166, 2007.

[5] C. H. Seah, S. Mridha, and L. H. Chan, "DC/pulse plating of copper for trench/via filling," J. Mater. Process. Technol., vol. 114, no. 3, pp. 233-239, 2001.

[6] J. Lu, M. Wang, X. Deng, J. Yan, J. Yun, and S. Jiao, "Evaluation of K3Fe(CN)6 on Deposition Behavior and Structure of Electroless Copper Plating,” Electrochemistry, vol. 87, no. 4, pp. 214-219, 2019.

[7] M. Galindo, P. Sebastián, P. Cojocaru, and E. Gómez, "Electrodeposition of aluminium from hydrophobic per fl uoro-3-oxa-4 , 5 dichloro-pentan-sulphonate based ionic liquids," J. Electroanal. Chem., vol. 820, no. January, pp. 41-50, 2018.

[8] N. Ciacotich, R. U. Din, J. J. Sloth, P. Møller, and L. Gram, “An electroplated copper-silver alloy as antibacterial coating on stainless steel," Surf. Coatings Technol., vol. 345, no. April, pp. 96-104, 2018.

[9] R. SEKAR, "Synergistic effect of additives on electrodeposition of copper from cyanide-free electrolytes and its structural and morphological characteristics," Trans. Nonferrous Met. Soc. China (English Ed., vol. 27, no. 7, pp. 1665-1676, 2017.

[10] C. D. Gu, Y. H. You, X. L. Wang, and J. P. Tu, "Electrodeposition, structural, and corrosion properties of Cu films from a stable deep eutectics system with additive of ethylene diamine," Surf. Coatings Technol., vol. 209, pp. 117-123, 2012.

[11] C. Gabrielli, P. Moçotéguy, H. Perrot, and R. Wiart, "Mechanism of copper deposition in a sulphate bath containing chlorides," J. Electroanal. Chem., vol. 572, no. 2, pp. 367-375, 2004.

[12] S. S. Abd El Rehim, S. M. Sayyah, and M. M. El Deeb, "Electroplating of copper films on steel substrates from acidic gluconate baths," Appl. Surf. Sci., vol. 165, no. 4, pp. 249-254, 2000.

[13] R. SEAKR, "Microstructure and crystallographic characteristics of nanocrystalline copper prepared from acetate solutions by electrodeposition technique," Trans. Nonferrous Met. Soc. China (English Ed., vol. 27, no. 6, pp. 1423-1430, 2017.

[14] S. Genna, A. Simoncini, V. Tagliaferri, and N. Ucciardello, "Optimization of the Sandblasting Process for a Better Electrodeposition of Copper Thin Films on Aluminum Substrate by Feedforward Neural Network," Procedia CIRP, vol. 62, pp. 435-439, 2017.

[15] M. Kanungo, V. Chakravarty, K. G. Mishra, and S. C. Das, "Influence of perchloric acid on the kinetics of immersion plating of copper onto aluminium," Hydrometallurgy, vol. 61, no. 1, pp. 1-11, 2001.

[16] J. H. Ai, S. P. Liu, N. A. Widharta, S. Adhikari, J. W. Anderegg, and K. R. Hebert, "Copper layers deposited on aluminum by galvanic displacement," J. Phys. Chem. C, vol. 115, no. 45, pp. 22354-22359, 2011.

[17] A. Augustin, P. Huilgol, K. R. Udupa, and U. Bhat K, "Effect of current density during electrodeposition on microstructure and hardness of textured $\mathrm{Cu}$ coating in the application of antimicrobial Al touch surface," $J$. Mech. Behav. Biomed. Mater., vol. 63, pp. 352-360, 2016.

[18] W. Dong, J. Zhang, J. Zheng, and J. Sheng, "Self-annealing of electrodeposited copper thin film during room temperature storage," Mater. Lett., vol. 62, no. 10-11, pp. 1589-1591, 2008.

[19] N. Sallee, M. Cromer, and O. Vittori, "Electroplating of Copper on Aluminium with Direct and Pulsed Currents Electroplating of Copper on Aluminium," Can. Metall. Q., vol. 33, no. 2, pp. 155-162, 1994.

[20] D. Grujicic and B. Pesic, "Electrodeposition of copper: The nucleation mechanisms," Electrochim. Acta, vol. 47, no. 18, pp. 2901-2912, 2002.

[21] Z. Z. Tasic, M. M. Antonijevic, M. B. Petrovic Mihajlovic, and M. B. Radovanovic, "The influence of 
synergistic effects of 5-methyl-1H-benzotriazole and potassium sorbate as well as 5-methyl-1H-benzotriazole and gelatin on the copper corrosion in sulphuric acid solution," J. Mol. Liq., vol. 219, pp. 463-473, 2016.

[22] M. B. Radovanović and M. M. Antonijević, "Protection of copper surface in acidic chloride solution by non-toxic thiadiazole derivative," J. Adhes. Sci. Technol., vol. 31, no. 4, pp. 369-387, 2017.

[23] S. C. B. Gopinath et al., "Photovoltaic and Antimicrobial Potentials of Electrodeposited Copper Nanoparticle," Biochem. Eng. J., vol. 142, no. September 2018, pp. 97-104, 2018.

[24] J. A. Khamaj, "Comparison of Potentiodynamic Polarization and Weight Loss Measurement Techniques in the Study of Corrosion Behavior of $6061 \mathrm{Al} / \mathrm{SiC}$ Composite in $3.5 \mathrm{M} \mathrm{NaCl}$ Solution," Asian J. Appl. Sci., vol. 3, no. 2, pp. 264-270, 2015.

[25] B. Soegijono, F. B. Susetyo, H. A. Notonegoro, and M. C. Fajrah, "Electrochemical Behavior, Structure, and Morphology of Electrodeposited Nickel on Copper Alloy Prepared from Sulfate Bath without Additive Addition," Flywheel, vol. 6, no. 1, pp. 6-12, 2020.

[26] D. Wang, B. Xiang, Y. Liang, S. Song, and C. Liu, "Corrosion control of copper in 3.5 wt.\% NaCl Solution by Domperidone: Experimental and Theoretical Study,” Corros. Sci., vol. 85, pp. 77-86, 2014.

[27] F. M. Al Kharafi, I. M. Ghayad, and R. M. Adallah, "Sulfide induced intergranular corrosion of copper in salt water containing benzotriazole,” e-Journal Surf. Sci. Nanotechnol., vol. 9, no. August, pp. 306-310, 2011. 